\title{
Commute Responses to Employment Decentralization: Anticipated versus Actual Mode Choice Behaviors of New Town Employees in Kunming, China
}

\author{
Xin Yang ${ }^{\text {a* }}$, Jennifer E. Day ${ }^{a}$, Brian Casey Langford ${ }^{b}$, Christopher R. Cherry ${ }^{\mathrm{c}}$, \\ Luke R. Jones ${ }^{\text {d }}$, Sun Sheng Han ${ }^{\text {a }}$, Jingyi Sun ${ }^{\text {f }}$ \\ ${ }^{a}$ Faculty of Achitecture, Building and Planning, The University of Melbourne, MSD Bldg., Masson Road, Victoria 3010, \\ Australia \\ ${ }^{b}$ Center for Transportation Research, The University of Tennessee-Knoxville, 309 Conference Center Blgd., Knoxville, TN \\ 37996-4133, USA \\ ${ }^{c}$ Department of Civil \& Environmental Engineering, The University of Tennessee-Knoxville, 321 John D. Tickle Bldg., \\ Knoxville, TN 37996-2313, USA \\ ${ }^{d}$ Department of Economics and Finance, Valdosta State University, Harley Langdale, Jr. College of Business Administration, \\ Valdosta, GA 31698-0075, USA \\ ${ }^{f}$ Faculty of Transportation Engineering, Kunming University of Science and Technology, Kunming, China, 650500
}

\begin{abstract}
This study examines workers' mode-choice responses to a typical job decentralization policy implemented in China's urban development - government job relocation (GJR) to new towns in the urban periphery. Broadly, the literature suggests that job decentralization tends to increase car commuting; however, little is known about the effects of China's GJR initiatives on individuals' commuting mode choices. Using Kunming as a case study, this study examines how workers' commuting mode choices have shifted in response to GJR policy. Our study analyzes two travel survey datasets that span the job relocation process: 1) stated preference (SP) data on workers' anticipated mode choices after a move of workplace to a planned new town; and 2) revealed preference (RP) data on workers' actual choices of commuting mode after their jobs were moved. The findings suggest that after job relocation, workers' actual commuting modes shift from more sustainable modes towards cars. The determinants of workers' mode choices differ substantially between the hypothetical and actual setting of job relocation. The anticipated mode choices are largely determined by socio-demographic characteristics whereas the actual mode choices are strongly influenced by travel time and housing locations. The evidence from this study offers two important implications for future planning practice of job decentralization. First, planners and policy-makers should be skeptical about the transportation benefits of job decentralization. Second, while SP surveys can assist planners to predict individuals' mode-choice responses, the robustness of SP results should be carefully assessed before translating into the evidence base for informing job decentralization policy-makings.
\end{abstract}

Keywords: Employment decentralization; Commuting mode choice; Stated preference; Revealed preference; New town development; China

\section{Introduction}

This study generates evidence about Chinese workers' mode-choice responses to peri-urban job relocation using both stated and revealed preference data. In the field of urban transportation research, the impact of employment decentralization on commuting mode

${ }^{*}$ Corresponding author. Tel.: +61-433-811-207;
E-mail address: x.yang@ student.unimelb.edu.au 
choice has been explored in a sizable body of literature over the past few decades. This paper makes two significant contributions to this body of work. First, it examines a particular set of Chinese policies that have been gaining momentum in recent years - a set of policies that have been implemented in a large number of cities across the nation despite significant evidence that the opposite of the intended effect might occur. Second, this work extends the work on mode shifts to a new location: a second-tier city in China's Yunnan Province. Third, the study compares stated- and revealed-preference studies to better understand the alignment between these types of data in this new context.

There is strong evidence in the literature that the overall characteristic of the modal effect of employment decentralization is featured by a shift away from sustainable form(s) of transportation to private automobile (Cervero and Landis, 1992, Cervero and Wu, 1998, Yang, 2010, Vale, 2013). This evidence casts doubt on the environmental benefits of employment decentralization that are often acclaimed in urban spatial plans, e.g., reducing inter-zonal commute, reducing traffic congestion in the urban core, and moving jobs closer to workers' residence. While the established knowledge is evident in North American and European cities as well as in a limited number of large cities in Asia, not much is known about the applicability of the current knowledge in other less-researched geographical context, such as small-medium cities in developing countries. Few studies have examined the practice of decentralizing government offices (exceptions being, Sim et al., 2001, Burke et al., 2011).

In this study, we aim to better the current understanding about the impact of employment decentralization on workers' commute mode choice, by focusing on a particular type of employment decentralization policy in China - government-led job decentralization to new towns in the urban periphery. As documented in some previous studies, government-led job decentralization practice, or government job resettlement (GJR) in short, is often a strategy for China's new town development, with the aim at incentivizing decentralization of employment and population to new towns (Liu et al., 2012, Yang et al., 2015, Yang and Day, 2015, Yang et al., in press). This strong policy invention is characterized by the relocation of public-sector jobs from central-city locations to new towns in the urban fringe. Affected public-sector workforce ranges from local government workers to employees of universities and state-owned enterprises. To our knowledge, little research has examined the modal effect of the GJR policy in China.

Using Kunming in southwestern China as a case study, this paper addresses two main research questions on workers' commute responses to the GJR policy. First, we examine: How did workers' adjust their commuting mode choices in response to job relocation to a new town? Second, we compare workers' anticipated and actual travel behavioral responses to the GJR policy. Question examined in this second research activity is: To which extent do workers' anticipated and actual mode choice behaviors align with each other?

This study is facilitated by a rare opportunity of research collaboration between two teams that independently-designed and -collected survey datasets spanning the job resettlement process in Kunming. Unlike the existing studies introduced above, our richer empirical setting enables transportation researchers and planners to have a more complete understanding of the dynamics in individuals' mode choice behaviors in response to job decentralization policy. That is, on top of generating the first piece of evidence on the modal effect of China's GJR policy, this study is also the first one in the English literature incorporating both stated and revealed choice data to explore commuting mode choices among the decentralized workforce ${ }^{1}$ (see, for an earlier study in Danish language, Møller and Næss, 2000). The latter offers valuable insights for the wider literature into the robustness of

\footnotetext{
${ }^{1}$ It is worth noting that the earlier study by Møller and Næss (2000) in Danish-language does combine the stated and revealed preference data to examine workers' anticipated and actual commuting behavior in response to workplace relocation in a Danish city. We would like to thank one of the anonymous reviewers for recommending this. However, due to the language barrier, we choose not to represent this study in our paper and suggest readers to consult Møller and Næss's (2000) study if their language capacity allows.
} 
stated choice experiments in predicting individuals' travel behavioral responses to employment decentralization policy.

The remainder of this paper is organized in four parts. Section 2 presents our literature review. It is followed by a description of research methodology (Section 3). Then, Section 4 presents and discusses results from our data analysis. Section 5 summarizes key findings, draws conclusions and makes policy and research implications.

\section{Literature Review}

Since the mid-1960s, several empirical studies have explored changes in workers' commute mode choice associated with employment decentralization to suburban areas. It is worth noting that this context of intra-metropolitan decentralization of jobs is different from its intra-regional counterpart, e.g., relocating jobs from Central London to Durham in the extended region as cited in Daniels (1972). Given studies published before 1990 (e.g., Wabe, 1967, Daniels, 1972, Daniels, 1981) have been discussed in a comprehensive review by Cervero and Landis (1992), our study focuses on reviewing studies generated in the 1990s and afterwards - the particular period when the surge of studies on the modal effect of employment decentralization occurred. In the following sections, we limit our review to studies published in English, in order to ensure a complete understanding of the knowledge claims in those reviewed studies. For studies published in other languages, e.g., Danish and Norwegian, we recommend the readers to refer to an excellent review in the Nordic context by Næss (2012).

As we will elaborate below, while there is a general consensus that job decentralization tends to encourage car commuting, a certain degree of inconsistency does exist in the effect of job decentralization on other travel modes. On one hand, it is not entirely surprising to notice the increased car commuting resulted from job decentralization, given employment subcenters are located outside the urban core and the accessibility by public transport could be lower than inner-city job locations. On the other hand, although job decentralization could be expected to bring jobs closer to workers' residence and thus discouraging car commuting, a number of studies have theorized the mechanism in which job location is only a subset of the wide range of factors that could be expected to influence individuals' mode choice behavior (cf. Van Acker et al., 2010, Næss, 2012, De Witte et al., 2013, for an extended discussion). Furthermore, the linkage between job location and car use is strongly dependent on whether the workplace is centrally or peripherally located in the metropolitan area. In the context of European and North American cities, some key features of the built environment, e.g., job density, parking availability at the workplace and public transport accessibility, differ substantially between inner-city and suburban job locations (Næss, 2012). Therefore, it would be a rather simplified assumption to expect job decentralization alone to bring about the desirable changes in commuting mode choice.

Also, in light of the multitude of factors influencing mode choice behavior, the inconsistency in the effect of job decentralization on other forms of transport could be explained by possible differences in the above-mentioned key characteristics of the built environment that are highly dependent on whether the workplace is located in the inner-city or peripheral areas. The divergence could also be attributed to some unobserved characteristics of the study population (e.g., lifestyle, attitudes and perceptions), aside from those socio-demographics controlled for in the prior work.

Although it is out of the scope of this paper to generate a comprehensive assessment of the degree of alignment/divergence among the studies presented below, we take into account possible factors, especially characteristics of the built environment other than job decentralization, when discussing and comparing the existing knowledge on the modal effect of job decentralization. In doing so, it will be helpful to understand not only the previous results from diverse contexts but also the new piece of evidence that we will present in the current paper.

\subsection{Empirical evidence in cities outside China}


The international work on the modal effect of job decentralization is predominantly generated in North American (Cervero and Wu, 1997, Cervero and Wu, 1998, Cervero and Landis, 1992) and European countries (Næss and Sandberg, 1996, Banister et al., 1997, Alpkokin et al., 2008, Aguiléra et al., 2009, Vale, 2013), with an exception of Singapore in the Asian context (Sim et al., 2001). Regardless of the geographical differences between American and European cities, longitudinal studies overwhelmingly suggest that job decentralization gives rise to an increase in car commuting, and much of the cross-sectional analysis indicates that private car commuting accounts for the largest share among employees in the employment sub-centers. Specifically, cross-sectional analysis indicates that employees in suburban areas tend to have a higher proportion of car commuting and lower proportions of commuting by sustainable transportation modes, compared with their inner-city counterparts (see, for example, Cervero and Landis, 1992, and an excellent review of studies in the Nordic context by Næss, 2012). Much of the longitudinal research in North American and European cities further suggests that employment decentralization leads to a significant shift in mode share from public transit to automobile (Cervero and Landis, 1992, Cervero and Wu, 1998, Vale, 2013).

In their study in San Francisco Bay Area, Cervero and Landis (1992) suggest that among 320 workers whose jobs were relocated from the city center to suburban areas, workplace relocation led to a significant shift from public transport to drive-alone on commuting trips. This study further indicates that the impact of employment decentralization on modal split is stratified in respect to workers' housing location choices after workplace relocation. Specifically, while a sharp decline in transit mode share is observed across all four types of housing location choices, workers, who continued to live in the central city, experienced the greatest increase in the mode share of both drive-alone and shared ride, compared with their counterparts who remained residences in suburbs, moved residences from downtown to suburbs and moved residences between different suburbs.

Based on a cross-sectional analysis, Cervero and Wu (1997) examine characteristics of mode share across four different tiers of employment centers that emerged in the San Francisco Bay Area. This study indicates that drive-alone accounts for the largest mode share for each type of employment center. However, the denser the employment centers are, the smaller share of drive-alone commuting. Employment centers with higher job density are also associated with greater shares of non-automobile modes, i.e., public transit, walking and cycling.

Focusing again on the emergence of employment sub-centers in the San Francisco Bay Area, Cervero and Wu (1998) conduct a longitudinal study on changes in commuting patterns during the period of 1980-1990. This study suggests that employment sub-centering in the Bay area over the 1980s was associated with a notable shift from public transit to drive-alone on the journey to work, which is consistent with the prior work by Cervero and Landis (1992). In comparison to sub-centers, this study identifies that downtown San Francisco, where core employment centers were located, experienced the greatest decline in public transit mode share. Overall, given driving-alone was the dominant commute mode in both 1980 and 1990, this study indicates that employment decentralization in the Bay Area has little impact on altering workers' habitual preference for automobile travel.

In the European context, Næss and Sandberg (1996) examine the characteristics of modal split across a selection of six workplaces at different distances from downtown Oslo, Norway. Among these workplaces, this study suggests that a great range exits in the proportions of commuting distances travelled by private car (12\% to $89 \%)$ and in those proportions by public transport (2\% to $86 \%$ ). This study further indicates that around half of the variations in the proportion of commuting distances travelled by car can be explained by six variables (ranked from the highest to the lowest effect): building density in the surrounding area of the workplace, car ownership, distance from the workplace to the downtown, errands in commuting trip, possession of a driving license, and number of wage earners in the household. Except for building density, all variables are positively correlated with the proportion of commuting distance travelled by car. 
Banister et al. (1997) offer valuable insights into the modal effect of planned decentralization to two new towns in Europe: 1) Milton Keynes new town in the United Kingdom (UK); and 2) Almere new town in the Netherlands. In the case of Milton Keynes, this study finds that $60 \%$ of the residents work locally, which is in line with the designated goal for this new town. That is, "[t]he original Master Plan aimed for a balance of housing and employment so that the city could be self-contained without large numbers of people needing to commute in or out" (p. 133). However, similar to the San Francisco Bay Area discussed above, the majority (about 75\%) of the survey respondents in Milton Keynes commute by car. The share of public transport and walking on work trips accounts for only $12 \%$ and $10 \%$, respectively. In comparison, while the Dutch new town Almere has a higher level of out-commuting (60\% in 1980 and $71 \%$ in 1991), there is a much greater share of walking and cycling on working trips.

Alpkokin et al. (2008) examine the commuting outcomes of the clustered pattern of employment growth in Istanbul between 1985 and 1997. In relation to commute mode share, this research suggests that commuting by public transit accounts for the largest modal share (58\%) for the old CBD zone in Istanbul in 1997. Meanwhile, moderate variations in transit modal share exist across different employment sub-centers, ranging from 39\% to 53\%. These results appear to be contradictory to the dominance of drive-alone commuting observed in San Francisco as discussed above (Cervero and $\mathrm{Wu}, 1998$ ). However, since this study does not report longitudinal result on shifts in commuting mode share, it is unclear about the modal effect of employment decentralization in Istanbul during the study period.

In another European city, Aguiléra et al. (2009) examine changes in workday travel patterns of central city residents that have occurred during employment decentralization in Paris metropolitan area between 1983 and 2001. During the two-decade period, the central city of Paris experienced an $11.5 \%$ decline of job numbers, while suburban areas had a net job growth of $18 \%$. In relation to shifts in travel mode choices for all types of trip purposes among central-city residents, this study suggests that there is a slight decrease in car use (26\% to $23 \%$ ) and a significant increase in two-wheeled vehicles (1\% to $4 \%$ ). For other transportation modes, the share remains the same over the study period. However, since this study is confined to changes in the modal split for all trip purposes on a given workday, it offers limited insights into understanding how central-city residents have adapted their choices of commuting mode during the process of employment decentralization in the Paris metropolitan area.

In a more recent study, Vale (2013) explores the commuting outcomes of workplace relocation to a suburban employment center in Lisbon, Portugal. Survey results suggest that for the sample as a whole, workplace relocation has led to a significant increase in car commuting $(+10.9 \%)$, accompanied by a decrease in the share of walking $(-4.2 \%)$ and public transit $(-11.9 \%)$. In addition, this study points out that workplace relocation has less impact on commuting time than commuting distances, and that variations in commuting-time changes are related to workers' former job locations. At a finer scale based on former job location, this study indicates that workers, whose workplace was previously located in the central city, were most affected in terms of mode shifting to car commuting (31.3\% of this sub-sample). Together, these findings indicate that after workplace relocation to a suburban employment center, workers tend to adjust their commuting mode to faster means of transport in order to keep commuting time within an acceptable threshold.

Contrary to the above body of literature, the research in Singapore indicates different outcomes of job decentralization. Sim et al. (2001) suggest that among employees working in a major employment sub-center in Singapore - Tampines Regional Center, a vast majority of them $(78.6 \%)$ commute by public transport whereas a very marginal proportion $(5.2 \%)$ driving to work. This study indicates that the dominance of using public transport for work trips can be attributed to not only the good public transport services in the Tampines, but also the high level of accessibility to public transport stations by walking. Another interesting feature of this study is the inclusion of government job resettlement in the job decentralization program, rather than having an exclusive focus on private firm relocation as performed in the aforementioned studies. 


\subsection{Empirical evidence in the context of Chinese cities}

In recent years, a number of studies have examined the impact of employment decentralization on commuting mode choice in China. However, since all of these studies focus on Beijing, it is yet to know whether the current empirical evidence could be generalized to other Chinese cities that have been pursuing employment decentralization to new towns over the past decade.

Through analyzing household surveys collected in 1996 and 2006, Yang (2010) suggests that considerable changes in commuting mode choice have occurred during the formation of multiple employment sub-centers in Beijing. Specifically, although there is a significant decrease (10\%) in cycling mode share, cycling still marks the dominant commuting mode in each of the study time point (53\% and 43\% in 1996 and 2006, respectively). For the second primary commuting mode - bus, its mode share remains largely unchanged over the study period, echoing the stable mode share of public transit in Paris as discussed previously (Aguiléra et al., 2009). At the same time, walking - the third primary commuting mode experienced an increase by about 5\%. In relation to automobile commuting (including taxi), a 10 percent increase is observed during the 10-year period ending in 2006. In general, these distributions are quite different from those findings generated in North American and some European cities discussed previously. But, this study identifies that the characteristics of commuting modal split differ substantially between car owners and non-owners, partially echoing the aforementioned significance of car ownership to commuting distances travelled by car observed in Oslo (Næss and Sandberg, 1996).

In a follow-up study, Yang et al. (2012) examine the transportation outcomes of clustered development in Beijing. This study groups travel survey data - the 2006 dataset used in Yang's (2010) study - according to three different zones: 1) the central city area, 2) suburban areas where the designated clusters are located, and 3) hybrid areas that sit inbetween the first two zones. The zonal analysis suggests quite moderate variations in modal split across different zones - non-motorized modes generally accounts for about half of the mode share, public transport for around one third, and automobile (including taxi) for the smallest share in 2006. Despite this general pattern, suburban areas are found to have the highest percentage of active travel and the lowest share of public transit for work trips. This study was not longitudinal, so the results are less robust than other evidence. Still, that car trips are higher in suburban areas in this study suggests that suburban moves in Chinese cities may increase car use.

In a more recent study, Lin et al. (2015) suggest that commuting patterns vary significantly across four case study employment sub-centers in Beijing, based on a travel survey collected from 578 respondents who work in these sub-centers in 2012. For each of the four sub-centers, while the majority of workers commute by public transport, the proportion of car commuting is sizeable. Moreover, this study identifies that certain variations do exist in car mode share across different sub-centers. Also, for non-motorized mode share, although it accounts for a relatively equal proportion (around 16\%) for all three sub-centers in suburban areas, the corresponding share is considerably smaller for the CBD. These results extend the evidence from earlier studies conducted by Yang (2010) and Yang et al. (2012), both of which concludes that there seems to be no spatial variation in modal split accompanying the polycentric development in Beijing. However, since this study does not include longitudinal analysis on shifts in sub-center workers' mode choices, the modal effect of employment decentralization in Beijing remains to be further explored.

So far, little research has explored the modal effect of government-led employment decentralization in China. Recent studies point out that employment decentralization in Chinese cities, especially for non-megacities, often occurs in a strong state-led manner. That is, the relocation of public-sector jobs from the central city to new towns is designated as a key strategy to stimulate the planned decentralization of jobs and population in metropolitan

areas. Government job resettlement (GJR) programs have been implemented in several medium-sized cities across China, e.g., Kunming, Xi'an, Hefei, Hangzhou, Qingdao, Erdos, 
and Lanzhou (see for an extended discussion, Yang et al., 2015, Yang and Day, 2016). Such involvement of GJR programs, along with the relatively low level of job mobility for publicsector workforce in China, depicts a unique feature of employment decentralization in Chinese cities.

\subsection{Summary}

Our review of the literature suggests that there is no strong theoretical basis to expect job decentralization policy alone to reduce car commuting. Within the body of empirical studies, the research in North American and European cities overwhelmingly indicates that job decentralization tends to increase car commuting. This status of knowledge also applies to China's mega city - Beijing. However, it is yet to understand whether the knowledge can be generalized to less-researched contexts, such as the practice of decentralizing government jobs and the geographical context of smaller-medium cities in developing countries. Within the context of Chinese cities, the impact of GJR policy on workers' commuting mode choice remains unexplored. This study responds to this knowledge gap and examines workers' mode-choice responses to the GJR policy in a medium-sized Chinese city, Kunming. The next section presents the method.

\section{Method}

We conduct a case study in Kunming, China to add the first piece of evidence on the impact of the GJR policy on workers' commuting mode choices. As another unique contribution of this study, we incorporate both stated and revealed preference data to examine dynamics in workers' commuting mode choice in response to the implementation of GJR policy in Kunming. This rich empirical setting not only extends the analytical framework used in previous research, but also offers important insights into the strength and weakness of stated preference (SP) survey in predicting individuals' mode-choice responses to the planned urban decentralization practice.

\subsection{Research questions}

In this paper, we examine two main research questions on workers' anticipated and actual commute responses to GJR policy in Kunming: 1) How did workers' adjust their commuting mode choices in response to job relocation to a new town? and 2) To which extent do workers' anticipated and actual mode choice behaviors align with each other? The research plan is visualized in our analytical framework (see Figure 1).

These primary questions are explored by addressing the following specific questions (SQ):

SQ-1: What changes in mode choice did workers anticipate to occur if their jobs would be moved to new town?

SQ-2: What changes have occurred in workers' actual commuting mode choice, from before to after job relocation to new town?

SQ-3: What factors are influential to workers' anticipated mode choice in response to the planned job relocation program?

SQ-4: What factors have shaped workers' actual commuting mode choice after their jobs were moved to new town?

SQ-5: Do those determinants of anticipated mode choice align with their actual counterparts, in relation to magnitude and direction? 


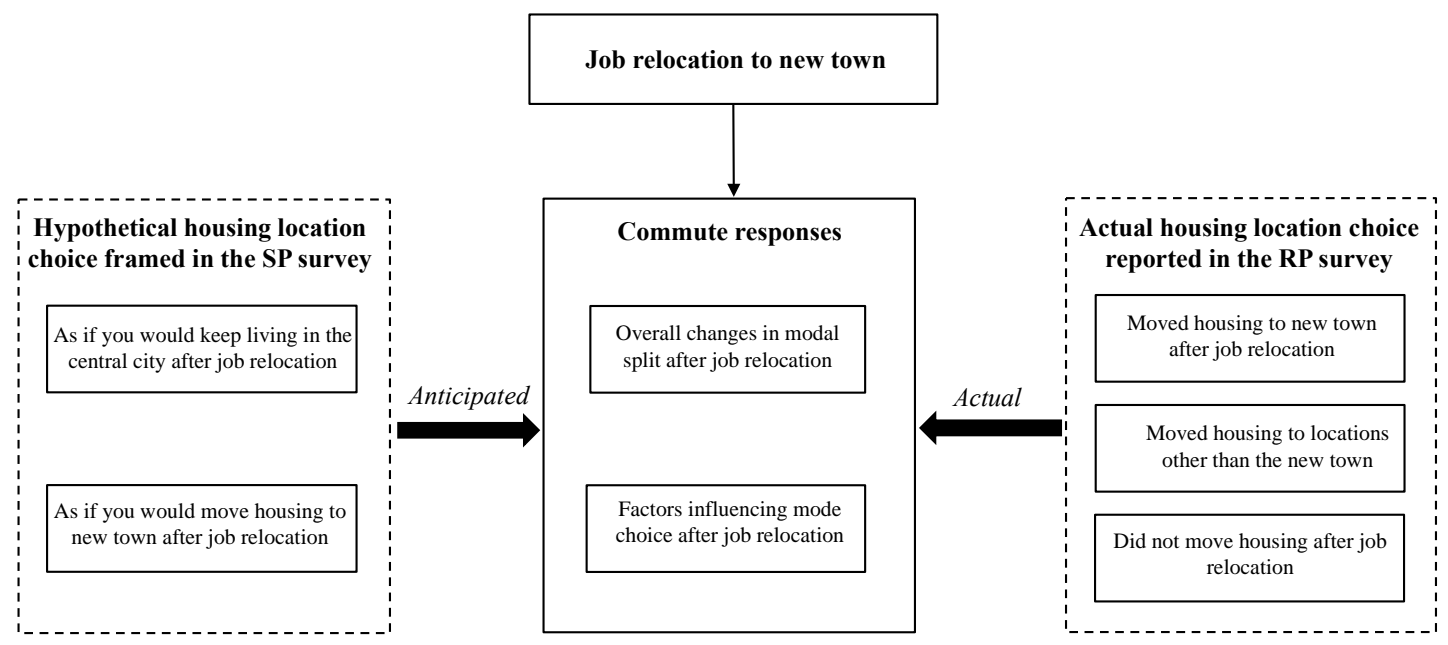

Figure 1. An analytical framework on workers' anticipated versus actual commute responses to GJR program in Kunming

\subsection{Case study area}

Our case study city Kunming is the capital city of Yunnan Province in southwestern China. Kunming started new town development in 2003. As we discuss below, the staged implementation of GJR in Kunming's new town development provides an interesting case to examine workers' commuting behavioral responses to employment decentralization policy. Our case study selection satisfies three major criteria for a single-case study design - that is, a critical, common and longitudinal case for inquiring into the phenomenon of interest (Yin, 2014, pp. 51-53). Given our upcoming paper (Yang et al., in press) provides an extended description of the policy background of GJR in Kunming, this section intends to briefly outline some key facts in our empirical setting, instead of duplicating too much information.

In May 2003, Kunming formulated a strategic vision for metropolitan development $-A$ Modern New Kunming. A structural element of this strategic plan is to transform the city's urban form from mono-centric towards a polycentric pattern. There are four clusters designed in this strategic plan: 1) the central city; 2) Chenggong New Town located in the eastern part of Kunming; 3) Xinjie New Town in the south; and 4) Haikou New Town in the west. According to Kunming Master Plan (2008-2020), among the three planned new towns, Chenggong was designated as the principle sub-center to function as the city's new CBD by 2020. It is expected to house central-city economic activities, e.g., administrative, higher education and producer service activities (KMUPDI, 2012, China.org.cn, 2014). Chenggong New Town is about $30 \mathrm{~km}$ away from the central city, linked by three arterial roads and one toll road. A metro line (Line 1) was put in use in May 2014 to link Chenggong to the central city.

In early 2011, Kunming implemented the GJR policy, relocating Kunming Municipal Government and subsidiary departments from the central city to Chenggong New Town. Around the same time, several other public-sector institutions moved to Chenggong, including some departments of five universities and one large state-owned enterprise. The ongoing government-led job decentralization to Chenggong will extend into health care and non-tertiary education sectors (YNPG, 2015).

This staged implementation of GJR policy in Kunming offers a dynamic empirical setting to examine workers' commute responses to the state-led employment decentralization policy in Chinese cities. To our knowledge, little research has been published on the impact of China's GJR policy on workers' commuting behaviors. In view of the mixed empirical results presented in Section 2, it is unclear how workers have adjusted their mode choices after their jobs had been moved to new towns. In addition, it is also unknown about dynamics in individuals' mode choice decisions when they are facing the planned workplace relocation program. 
As we discuss in the next section, the timing of our SP and RP survey data collection spans the job relocation process in Kunming. As such, it allows us to conduct the first inquiry into workers' anticipated and actual commute responses to GJR policy, thus contributing to enriching the current knowledge on the transportation outcomes of government-led employment decentralization in Chinese cities.

\subsection{Data}

The data used in this study comes from two sets of travel survey data independently collected by two research teams: 1) a SP survey data collected by the authors from the USA; and 2) a RP survey data compiled by the authors from Australia. As we present below, the timeframe of these two sets of survey data spans across the process of implementing GJR policy in Kunming. While the two sets of travel survey instruments were independently designed, they share a sizable proportion of common variables, facilitating a rare opportunity for a joint research into workers' commute responses to GJR policy.

About one year before implementing GJR policy in Kunming, the authors from the USA conducted a SP travel survey in Kunming between July and October in 2009. The SP survey was designed to serve a larger research project on individuals' choice of new transportation options between the central city of Kunming and Chenggong New Town. A total of 634 surveys were collected from four main groups of population who might eventually commute between the central city and the new town. These include: 1) public-sector employees who were facing the planned workplace relocation program to Chenggong; 2) university students whose departments were to be relocated to Chenggong; 3) existing residents of Chenggong; and 4) residents living in the central city.

Since this paper focuses on GJR program, the ongoing analysis only involves the first group of SP survey respondents. This subset of the SP sample was collected from 50 government employees, 50 university teachers and 50 health care workers, whose jobs were to be relocated to Chenggong. This population was selected because it was known that these types of jobs were slated for relocation to the new town. For each type of the professionals, an intercept sampling strategy was adopted at three places of work where these types of employees would report, which were known to be relocating to Chenggong. Surveyors approached individuals as they entered or exited the primary entry to a hospital, various university buildings, and an office building in central Kunming. Surveyors verified their employment type and offered the survey. If the survey was refused, no data was collected for that individual. Researchers continued intercepting employees until the target sample size was reached for each employment type, creating a representative cross-section of those who would potentially relocate to Chenggong New Town. After data screening, a total of 86 valid observations are analyzed in this study.

During October to December in 2014 - approximately four years after the GJR policy was implemented, the authors from Australia carried out a RP survey in Kunming to collect travel data for a larger research project on Kunming's GJR program. The RP survey instrument was designed to examine the travel welfare impact of GJR program on the affected population. The RP survey was collected from municipal government employees whose jobs were relocated from downtown Kunming to Chenggong New Town in early 2011. Respondents were recruited from government departments which had been relocated to Chenggong $^{2}$. 10 departmental heads cooperated with the research, consenting to allow recruiting and surveying of employees at the workplace on a weekday during work hours. No summary information was available about the total number of employees working in the offices or the number of relocated departments, so it is difficult to know how representative this sample is of the job-relocated population of employees. We are not able to reveal, due to privacy concerns, the departments that were surveyed in the RP survey, but we have no

\footnotetext{
${ }^{2}$ We note that the RP sample also has a control group of employees whose jobs were not relocated. Those findings are not presented here because they cannot be compared with a comparable SP dataset.
} 
reason to expect that the distribution of age, sex, seniority, and other relevant characteristics of this population differs from the general population of government workers in China.

In these 10 departments, all employees at their desks during the weeks of October to December 2014 were approached - in total, around 400 government workers. Of these, 287 respondents returned their completed survey questionnaires. After excluding largely incomplete surveys, a total of 211 valid surveys were collected, resulting in a final response rate of $52 \%$. For individual questions relevant to this study, the completion rate ranges from $91 \%$ to $100 \%$. After excluding missing data on a case-wise deletion basis, a total of 192 observations are analyzed in this study.

In relation to the choice data, public-sector participants in the SP survey were asked to report their current commuting mode and the transport means they would expect to use after job relocation to Chenggong New Town. The post-job-relocation phase was further divided into two hypothetical settings: 1) respondent lives in the central city after job relocation; and 2) respondent lives in the new town after job relocation. For each of the three time points, respondents were asked to select from an identical choice set: car, bus, subway, walk, and other mode. Subway is a hypothetical alternative that had been planned at the time of the SP survey but was not put in use until May 2014.

In the RP survey, participants were asked to report the primary transportation mode that they took to work on a typical working day before (i.e., July 2010) and after job relocation to Chenggong New Town (i.e., at the time of completing the survey in late 2014). The choice set consisted of five alternatives: car, public transport (including bus and subway), bicycle, walk, and shuttle-bus provided by employer. This choice set is slightly different from the one used in the SP survey. First, the 'public transport' option was used as an inclusive category, instead of specifying it into bus and subway. Second, the RP choice set explicitly specifies the bicycle and shuttle-bus ${ }^{3}$ options, instead of grouping them into the 'other' category as administrated in the SP survey.

An observant reader will notice that the RP choice set does not include the 'other' alternative. Indeed, the omission of the 'other' option might miss out 'taxi' and 'electric bike (e-bike)' - two important elements of Kunming's urban transportation system ${ }^{4}$. This was an unavoidable omission to the models, as these data were not collected for the RP sample. Such omission may somehow bias the RP results, but we consider that the degree of bias might not be large. We discuss this in the next two paragraphs.

In relation to taxi, it is rarely reported in the transportation literature that the study population used taxi as the primary commuting mode especially on a regular basis. Although a previous transportation study in China suggests that taxi accounted for 5\% of all trips in Kunming and Shanghai in 2003 (Cherry and Cervero, 2007), a more recent study in Beijing indicates that only $1.2 \%$ of the 745 respondents traveled to work by taxi in the year 2006 (Wang et al., 2011). On the other hand, in our empirical setting, Chenggong New Town is located in the urban fringe where taxi service is rarely provided; meanwhile, a one-way taxi trip from Chenggong to the central city normally costs for 100 CNY in 2014, about $3 \%$ of the average monthly income of RP respondents (we will return to this in Section 4.1). As such, it is very unlikely that people would use taxi as their primary commuting mode. Even if some participants did use taxi as their primary commuting mode, it is not impossible that they might choose the 'car' option in the RP choice set for the concern of having similar travel time.

\footnotetext{
${ }^{3}$ However, the shuttle-bus observations are not included in the proceeding analysis for two reasons. Frist, the fieldwork found out that shuttle-bus was not provided before job relocation (personal communication with some of the participants in the field). As such, the inference cannot be meaningfully made in relation to the change in shuttle-bus modal share occurred from job relocation - the treatment examined in this study. Second, after job resettlement, only two respondents chose shuttle-bus as their primary commuting mode. Such small number of responses does not allow sufficient variations to be estimated from discrete choice models. In fact, the inclusion of these two shuttle-bus observations in choice models will lead to a warning message of ' 2 observations are completely determined.'

${ }^{4}$ Motorcycle is banned in the main built-up areas of Kunming - essentially within the city's second ring road.
} 
With regard to e-bike, given the wording 'bicycle' used in the RP survey - zixingche (自 行车) in the Chinese version of survey questionnaire - literally encompasses both traditional bike and e-bike, and e-bike is officially classified into the bicycle category in Kunming, it is of a high possibility that people would report e-bike under the bicycle category. In this sense, the absence of the 'other' option would not substantially under-sample e-bike commuters. Even if a certain (we expect marginal though) amount of e-bike users might be pedantic with the wording and report their secondary commuting mode as if the e-bike option was unavailable, we expect that this would possibly introduce some bias to the mode share of public transport - somehow round up the transit modal split, to be more specific. According to a six-year (2006-2012) study on Kunming's e-bike use, over half of the sampled e-bike users would choose bus as an alternative mode if e-bikes were unavailable (Cherry et al., 2016). However, as stated, since the wording 'bicycle' is inclusive of e-bike, we expect that there would be a marginal likelihood for RP respondents to report alternative mode (e.g., bus) to e-bike.

Before proceeding to the next section, it is worth noting that certain bias in the ongoing analysis can result from four limitations in our dataset. First, as presented above, the sampling strategies and the response the sampling strategies used in 2009 and 2014 are not entirely random, but were systematically captured within the limitations of our accessibility to the study population. As a result, the lack of sample randomness could undermine the representativeness of the sample for the real situation in the study population. Second, since the sampling frame somewhat differs between the SP and RP sample, it is expected that there can be certain bias in comparing the convergence between workers' anticipated and actual commuting mode choices. Third, the omitted observations due to missing data can further reduce the representativeness of the sample and leads to some bias in the SP/RP model comparison. Last, due to the absence of 'taxi' in the RP choice set, it is possible that some respondents commuting by taxi might choose the car option in the choice set. Thus, the RP sample might overestimate workers' propensity to commute by car. We bear these limitations in mind and compare the SP and RP results with cautions in the proceeding sections.

\subsection{Data analysis procedure}

In order to address the set of research questions introduced previously, we apply two types of data analysis methods: 1) descriptive statistics on overall changes in anticipated/actual modal split; and 2) Multinomial Logit (MNL) modeling to identify significant factors influencing workers' anticipated/actual mode choice after job relocation. The procedure of data analysis is detailed as follows:

First, we analyze and compare changes in workers' anticipated and actual commuting mode choice from before to after job relocation. For each dataset, net changes in modal split are stratified with regard to housing location choices after jobs were moved to Chenggong New Town. Results from the descriptive statistics analysis are used to answer Specific Question 1 and 2 stated above: anticipated and actual changes in mode choice after job relocation, respectively.

Second, in order to look into the behavioral mechanism underlying workers' anticipated and actual mode choice responses - Specific Question 3 and 4, we conduct independent discrete choice analyses on each dataset using the MNL modeling framework. It is worth noting that while the SP and RP models are independently specified, predictors are limited to the set of matching independent variables between the SP and RP dataset. The purpose is to deliberately rule out compounding factors that might result in inconsistency between SP and RP model estimations. In doing so, modeling results from the SP and RP dataset can be reliably compared to indicate the accuracy of SP survey to predict individuals' travel behavioral responses to GJR policy.

Before proceeding to discuss the differences between the SP and RP results, a methodological issue of concern should be noted. In this study, car availability is among the set of matching explanatory variables between the SP and RP data and is included as a control 
variable in the MNL model comparisons. The purpose of including car availability is to implicitly account for the potential divergence between the SP and RP model estimations that might result from a substantial increase in car ownership in Kunming between 2009 and 2014. A recent travel behavior study in Kunming suggests that auto ownership increased significantly from 2006 to 2012 among the surveyed population (Cherry et al., 2016). The metropolitan travel survey further indicates that a sizeable increase in car mode share in Kunming occurred between 2006 and 2011, i.e., from 11\% to 20\% (Kunming Urban Transportation Institute, 2012, as cited in Cherry et al., 2016). It is plausible that the rising trend of car ownership in Kunming might persist for the RP survey in 2014, and thus widening the difference in car mode share between the SP and RP results.

Therefore, by including car availability as a control variable between the SP and RP model comparisons, our study is expected to reasonably control for the possible influence of the substantial change in car ownership on mode choice behavior between the times of the SP and RP investigations. This logic further goes that if the car availability variable is not included as a control variable, the intended SP and RP model comparisons might have a strong likelihood of overestimating the effects of other explanatory variables on the divergence between the anticipated and actual commute responses to GJR policy. This is due to the above-mentioned plausible association between the increase in car ownership and increase in car mode share in Kunming. Thus, we consider it is of necessity to include car availability as a control variable in the proceeding SP/RP model comparisons.

\section{Results and Discussion}

\subsection{Sample characteristics}

Respondents' socio-demographic characteristics are relatively similar between the SP and RP sample, though a small number of differences exist (Table 1 and Figure 2). For both samples, the majority of respondents have more than one working adults in their households. The proportion of respondents who have young child ( $<18$ years old) is comparable between the two samples - around half of the sample. Age is similarly distributed in all age groups, except for the youngest segment (18-25 years old). To be more specific, respondents in their late 20s and early 30 s accounts for the largest share of each sample, echoing the result that a sizeable proportion of respondents have young child. The SP and RP sample have a nearly identical share of respondents in each of the three age groups above 35. However, the SP sample has a much higher proportion (27\%) of young respondents (18-25 years old) who just enter the workforce, in comparison to the RP sample (7\%).

In addition, it is interesting to notice that while income is measured through different indicators - household yearly income used in the SP survey and respondents' individual monthly income in the RP survey -- both samples report incomes lower than the Kunming metropolitan average. The average household yearly income of SP survey respondents is $37,500 \mathrm{CNY}$ in 2009, which is 7,000 CNY lower than the average urban household income in Kunming in the corresponding year (Statistical Bureau of Yunnan Province, 2010). For RP survey respondents, the average monthly income is $2,995 \mathrm{CNY}$ in 2014 , equivalent to a yearly individual income of 36,000 CNY. This figure is 2,000 CNY lower (inflation rate adjusted), compared with the average wage of public-sector workers in Kunming in 2013 the latest Census data the authors can access (Statistical Bureau of Yunnan Province, 2013).

However, there are two noticeable differences between the SP and RP sample. First, while the gender split is almost even for the RP sample, respondents in the SP sample seem to be heavily drawn from female employees (about two thirds) whose jobs were to be relocated to Chenggong. Second, participants in the SP survey have a considerably lower rate of having car available to use in work trips than their RP counterparts (i.e., 38\% in the year 2009 versus $74 \%$ in 2014). This difference in car availability may result from the increasing rate of car ownership over the past years in Kunming (Cherry et al., 2016). Another plausible explanation is related to the larger proportion of female respondents and the larger proportion of young respondents (18-25 years old) in the SP survey. That is, women might not perceive 
a household car as an available transport option due to factors like lower driving skills and family power relationship in accessing cars in the household (Yang and Day, 2015, Yang and Day, 2016). For respondents in the 18 to 25 age group, since they by and large have just entered the workforce, their income level can be much lower than their senior counterparts. Therefore, this group could be expected to have a lower level of car ownership.

The characteristics of the SP in relation to gender split, car availability and young respondents, might lead to an underestimation of workers' anticipated choice of car in response to the hypothetical job relocation. Due to the lack of census data on the profiles of public-sector workers, it is out of the scope of this paper to estimate the exact degree and direction of bias in the SP and RP sample comparison. However, in view of the notable differences in gender split, car availability and the proportion of young respondents presented above, we will make a careful comparison of the SP-versus-RP model estimations on mode choice behaviors, especially for the effect of these variables (Section 4.3.2).

Table 1. Socio-demographic characteristics of the SP and RP sample

\begin{tabular}{|c|c|c|c|c|c|c|c|}
\hline \multirow[t]{2}{*}{ Data source } & \multirow[t]{2}{*}{ Sample size } & \multicolumn{3}{|c|}{ Individual characteristics } & \multicolumn{3}{|c|}{ Household characteristics } \\
\hline & & $\%$ Male & $\begin{array}{l}\text { Monthly income in } \\
2014(\text { CYN) }\end{array}$ & $\begin{array}{l}\% \text { Car } \\
\text { availability }\end{array}$ & $\begin{array}{l}\text { Yearly income in } \\
2009(\mathrm{CYN})\end{array}$ & $\begin{array}{l}\% \text { More than one } \\
\text { working adults }\end{array}$ & $\begin{array}{l}\% \text { Have young } \\
\text { kid }\end{array}$ \\
\hline SP sample & 86 & 34.9 & N/A & 38.4 & $37500(19444)$ & 73.3 & 41.9 \\
\hline RP sample & 192 & 53.7 & $2995(1141)$ & 74.0 & N/A & 85.4 & 51.6 \\
\hline
\end{tabular}

Notes:

1. 'N/A' indicates that the variable is not included in the sample.

2. Standard deviation in parenthesis.

3. Average incomes are estimated from mid-points of income categories.

4. $1 \mathrm{USD}=6.83 \mathrm{CNY}(2009), 1 \mathrm{USD}=6.14 \mathrm{CNY}(2014)$

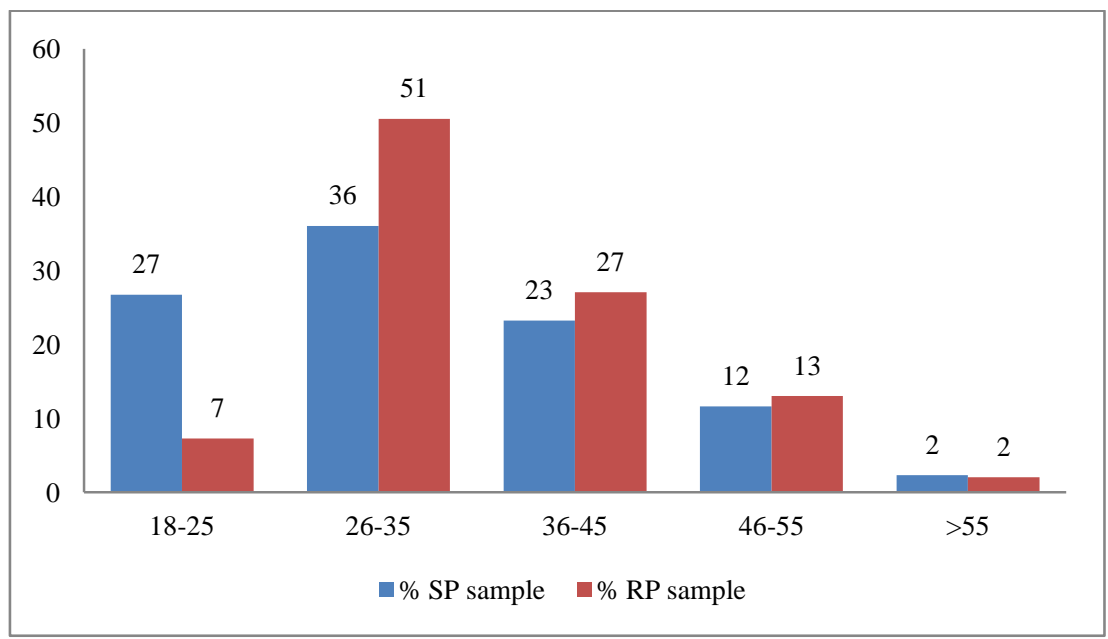

Figure 2. Age distribution of respondents in the SP and RP sample

\subsection{Anticipated versus actual changes in modal split}

The modal split results (Table 2 and 3) suggest that within each choice setting (i.e., the SP and RP survey, respectively), the impact of GJR policy on commuting mode choice tends to vary according to different types of housing location choice after job relocation. This overall transportation outcome echoes the aforementioned evidence observed in the San Francisco Bay Area (Cervero and Landis, 1992). However, in our empirical setting, we identify that considerable differences exist between respondents' anticipated and actual mode shifting behaviors in response to the intervention of job relocation policy. 
When facing the hypothetical situation of 'as if I would live in the central city after my job is moved to Chenggong New Town,' an overwhelming majority of SP survey respondents stated that they would take public transport to commute to their new workplace - 79\% anticipated using the subway and $12 \%$ using the bus. At the time of the SP survey, the subway was a hypothetical transport option in Kunming - it was not yet built. The development plan of this metro line had been announced at that time but the metro line linking Chenggong and the central city was not operated until May 2014. In comparison to the current mode shares at the time of completing the SP survey, there would a substantial shift to subway from all other transport means if respondents intended to live in the central city after job relocation. At the first glance, these results appear to depict a sustainable transportation outcome of GJR policy in Kunming, as workers were inclined to switch to public transport after job relocation. Nevertheless, this apparently sustainable outcome is somewhat undermined by the decrease of 29 percentage points in the anticipated use of walking when respondents would live in the central city after the hypothetical job relocation,

In comparison, the anticipated shift to public transport does not present in the actual choice setting. To be more specific, after jobs have been eventually relocated to Chenggong, among those respondents who continue living in the central city and commute to the new town, while half of them commute by public transport, a substantial proportion of this group drive to work (44\%). Among this group of central-city-living respondents, they experience a significant shift to car commuting (an increase of 25 percentage points) from sustainable transport means (i.e., public transport, cycling and walking) after job relocation to new town.

In the second hypothetical choice situation 'as if I would relocate to Chenggong New Town after my job is moved there,' the anticipated choice of subway in work trips is of the smallest share (2\%). The largest proportion of stated commuting mode is walking (37\%), and followed by car $(26 \%)$. The hypothetical situation of moving both job and home to new town is associated with a substantial switching from the anticipated choice of bus (a decrease of 23 percentage points) to all other modes in the journey to work. Nevertheless, SP respondents expect that the modal share of driving to work is anticipated to increase by 9 percentage points even in this case of co-locating job and housing in the new town, challenging the oftentouted transport benefit of employment decentralization in reducing car use.

Table 2. Changes in anticipated commuting mode share from before to after job relocation, SP sample

\begin{tabular}{|c|c|c|c|c|c|}
\hline \multirow[t]{2}{*}{$\begin{array}{l}\text { Commuting } \\
\text { mode }\end{array}$} & \multirow{2}{*}{$\begin{array}{l}\begin{array}{l}\text { Before job } \\
\text { relocation }\end{array} \\
\mathrm{N}(\%)\end{array}$} & \multicolumn{2}{|c|}{$\begin{array}{l}\text { If live in the central city after job } \\
\text { relocation }\end{array}$} & \multicolumn{2}{|c|}{$\begin{array}{l}\text { If live in the new town after job } \\
\text { relocation }\end{array}$} \\
\hline & & $\mathrm{N}(\%)$ & $\begin{array}{l}\text { Change in mode } \\
\text { share (percentage } \\
\text { points) }\end{array}$ & $\mathrm{N}(\%)$ & $\begin{array}{l}\text { Change in mode } \\
\text { share (percentage } \\
\text { points) }\end{array}$ \\
\hline Car & 14 (16.28) & $5(5.81)$ & -10.47 & $22(25.58)$ & 9.3 \\
\hline Walk & $27(31.40)$ & $2(2.33)$ & -29.07 & $32(37.21)$ & 5.81 \\
\hline Other & 14 (16.28) & $1(1.16)$ & -15.12 & 19 (22.09) & 5.81 \\
\hline Total & $86(100.00)$ & $86(100.00)$ & - & $86(100.00)$ & - \\
\hline
\end{tabular}

Note: Subway is a hypothetical alternative in the SP survey. This mode was not put in use until May 2014.

Similarly, these patterns of anticipated commute responses are identified in their actual revealed counterparts. Specifically, after both jobs and housing were actually moved to new town, car and walking accounts for the first two highest modal shares in work trips, i.e., $47 \%$ and $35 \%$, respectively. The large proportion of car commuting among this group of respondents echoes the aforementioned study conducted in the San Francisco Bay Area (Cervero and Landis, 1992) and Milton Keynes New Town, UK (Banister et al., 1997) whereas contrasts the case in Beijing (Yang, 2010) and Singapore (Sim et al., 2001).

In addition, after actually co-locating job and housing in the new town, a substantial shift occurs from transit (a decrease of 39 percentage points) to other transport means, especially 
for walking (an increase of 29 percentage points). The sharp increase in walking, accompanied by the jobs-housing co-location in Chenggong New Town, appears to lend support to the designated feature of new town development and the role of employment decentralization in triggering sustainable transportation outcomes. However, similar to the sizable increase in anticipated car commuting as if relocating both job and housing to new town as discussed above, a nearly identical increase is found in the actual choice of driving to work ( 8 percentage points) after both job and housing were relocated.

The higher share of car commuting in the RP data than that in the SP data should not be a surprise. On one hand, the greater share of driving to work in the RP study is plausibly attributed to the substantial increase in the overall car availability between the times of the SP survey in 2009 (38\%) and the RP survey in 2014 (74\%). On the other hand, as presented earlier, the effectiveness of employment decentralization in lowering car commuting depends on a multitude of factors, including immediate changes in trip attributes (e.g., travel distances), key features of the built environment (e.g., public transport accessibility) that are highly dependent on whether the workplace is centrally or peripherally located in the metropolitan area, and the characteristics of the affected population (e.g., sociodemographics, attitudes and lifestyles). Again, this demonstrates that it would be a rather simplified assumption to expect job decentralization alone to bring about desirable changes in commuting mode choice.

As an additional choice setting captured in the RP data, we surveyed the third type of housing location choice after job relocation, where residents moved housing to another place in Kunming that was neither the old residence or the new town (the last two columns of Table 3). This housing location choice accounts for $17 \%$ of the RP sample. Among those respondents who moved housing to elsewhere in the city after the GJR policy was implemented, an overwhelming majority of this group commutes to the new workplace by motorized mode $-53 \%$ by public transport and $41 \%$ by car. Changes in modal split after job relocation suggest a considerable shift from non-motorized mode (including walking and cycling) to otherwise (car and public transport). An even increase (12.5 percentage points) is observed in the share of car and public transport after job relocation.

Another key finding from the RP sample is that a considerable increase in car commuting presents across the whole RP sample - in addition to the increase existing in each of the three individual segments based on housing location choices discussed above. As Table 4 shows, after jobs were actually relocated to new town, there is a statistically significant increase in driving to work (17 percentage points). Moreover, the significant shift to car commuting is found to come from public transport and cycling, i.e., a statistically significant decrease of 15 and 5 percentage points, respectively. The share of walking in work trips does not experience significant change from before to after job relocation. Comparing to the prior work reviewed in Section 2, the pattern of modal switching after job relocation revealed in our study is consistent with the evidence from three longitudinal studies in cities outside China (Cervero and Landis, 1992, Cervero and $\mathrm{Wu}, 1998$, Vale, 2013), but largely differs from the only piece of longitudinal evidence generated in China (i.e., Beijing) (Yang, 2010).

\footnotetext{
${ }^{5}$ It would be an ideal inquiry if we could generate comparable results from the SP sample, regarding stated mode choices made from before to after job relocation. However, as stated previously, the SP mode choice data was separated into two phases after the planned GJR policy would be implemented. In this case, it is impractical to integrate two sets of stated mode choices into a single time point as "after job relocation," without distorting the nature of the SP data. Thus, we choose to only report the RP sample results on the aggregated changes in actual modal share from before to after job relocation (Table 4).
} 
Table 3. Changes in actual commuting mode share from before to after job relocation, RP sample

\begin{tabular}{|c|c|c|c|c|c|c|c|c|c|}
\hline \multirow[t]{2}{*}{$\begin{array}{l}\text { Commuting } \\
\text { mode }\end{array}$} & \multirow{2}{*}{$\begin{array}{l}\begin{array}{l}\text { Before job } \\
\text { relocation }\end{array} \\
\mathrm{N}(\%)\end{array}$} & \multicolumn{2}{|c|}{$\begin{array}{l}\text { Continue living in the central } \\
\text { city after job relocation }\end{array}$} & \multirow{2}{*}{$\begin{array}{l}\begin{array}{l}\text { Before job } \\
\text { relocation }\end{array} \\
\mathrm{N}(\%)\end{array}$} & \multicolumn{2}{|c|}{$\begin{array}{l}\text { Moved to new town after job } \\
\text { relocation }\end{array}$} & \multirow{2}{*}{$\begin{array}{l}\begin{array}{l}\text { Before job } \\
\text { relocation }\end{array} \\
\mathrm{N}(\%)\end{array}$} & \multicolumn{2}{|c|}{$\begin{array}{l}\text { Moved to elsewhere in the city } \\
\text { after job relocation }\end{array}$} \\
\hline & & $\mathrm{N}(\%)$ & $\begin{array}{l}\text { Change in mode } \\
\text { share (percentage } \\
\text { points) }\end{array}$ & & $\mathrm{N}(\%)$ & $\begin{array}{l}\text { Change in mode } \\
\text { share (percentage } \\
\text { points) }\end{array}$ & & $\mathrm{N}(\%)$ & $\begin{array}{l}\text { Change in mode } \\
\text { share (percentage } \\
\text { points }\end{array}$ \\
\hline Car & $17(19.32)$ & $39(44.32)$ & 25 & $28(38.89)$ & $34(47.22)$ & 8.33 & $9(28.13)$ & $13(40.63)$ & 12.5 \\
\hline Public transport & $50(56.82)$ & $46(52.27)$ & -4.55 & $33(45.83)$ & $5(6.94)$ & -38.89 & $13(40.63)$ & $17(53.13)$ & 12.5 \\
\hline Bicycle & $10(11.36)$ & $1(1.14)$ & -10.23 & $7(9.72)$ & $8(11.11)$ & 1.39 & $3(9.38)$ & $1(3.13)$ & -6.25 \\
\hline Walk & $11(12.50)$ & $2(2.27)$ & -10.23 & $4(5.56)$ & $25(34.72)$ & 29.17 & $7(21.88)$ & $1(3.13)$ & -18.75 \\
\hline Total & $88(100.00)$ & $88(100.00)$ & - & $72(100.00)$ & $72(100.00)$ & - & $32(100.00)$ & $32(100.00)$ & - \\
\hline
\end{tabular}

Table 4. Aggregated changes in actual commuting mode share from before to after job relocation, RP sample

\begin{tabular}{llllll}
\hline $\begin{array}{l}\text { Commuting } \\
\text { mode }\end{array}$ & $\begin{array}{l}\text { Before job } \\
\text { relocation } \\
\mathrm{N}(\%)\end{array}$ & $\begin{array}{l}\text { After job } \\
\text { relocation } \\
\mathrm{N}(\%)\end{array}$ & $\begin{array}{l}\text { Change in mode } \\
\text { share } \\
\text { (percentage points) }\end{array}$ & $\begin{array}{l}\text { McNemar's } \\
\text { chi2(1) }\end{array}$ & Prob > chi2 \\
\hline Car & $54(28.12)$ & $86(44.79)$ & 16.67 & 17.07 & 0 \\
Public transport & $96(50.00)$ & $68(35.42)$ & -14.58 & 10.32 & 0.0013 \\
Bicycle & $20(10.42)$ & $10(5.21)$ & -5.21 & 4.17 & 0.0412 \\
Walk & $22(11.46)$ & $28(14.58)$ & 3.12 & 0.86 & 0.3545 \\
Total & $192(100.00)$ & $192(100.00)$ & - & - & - \\
\hline
\end{tabular}




\subsection{Comparison between the SP and RP model estimations on mode choice after job relocation}

The foregoing discussion has compared the overall patterns of variances in anticipated and actual commuting choice behaviors after job relocation to a new town in Kunming's urban periphery. The above analysis captures different types of housing location choice after job relocation - an important aspect that has been largely absent in previous studies examining the impact of employment decentralization on commuting mode choice (except for Cervero and Landis, 1992). Descriptive statistics on modal split and mode switching reveal a considerable departure of the anticipated mode-choice responses from their actual counterparts, especially for the choice setting of living in the central city after job relocation.

However, it remains unaddressed about the possible causes underlying the SP/RP deviation in mode-choice responses to job relocation policy. In this section, we develop two sets of MNL model to identify significant factors influencing workers' anticipated and actual mode choice behaviors after job relocation. The SP and RP model estimations are compared to shed light on the possible factors underlying the divergence between the anticipated and actual commuting mode choice behaviors.

\subsubsection{The MNL modeling framework}

In each choice setting, we estimate the variability in workers' mode-choice responses after job relocation to Chenggong New Town. The MNL modeling framework is applied to estimate the relative probability of choosing car (the reference mode) versus each of the rest alternatives in the choice set.

In the RP model, we estimate 192 observations on actual commuting mode choice after jobs were moved to new town. The SP model estimates a combined dataset of 172 data entries on anticipated mode choice after job relocation. To be more specific, we combine two paired samples on anticipated mode choice as if jobs are moved to new town. The two specific framings on hypothetical housing locations - as if I live in the central city and as if I live in the new town after job relocation - enter the MNL model as an independent variable, as a way to account for the effect of housing location choice on anticipated commuting mode choice. Another main benefit of combining the paired samples on stated mode choice and controlling for housing location choice, is to ensure other possible determinants, than housing location choice, can be reliably compared between the SP and RP model estimations. Given the use of a combined dataset in the SP model, we adjust the standard errors for clustering on the same individual, in order to address the issue of potential non-independence of error terms associated with the inclusion of two observations of stated mode choice from the same respondent.

For both choice settings (i.e., SP and RP), the general structure of the observed utility function for a given alternative mode $(i)$ is shown in Eq. (1):

$$
\begin{aligned}
& V_{i}=\text { ASC }_{i}+{ }_{1 i} \text { Time }_{i}{ }^{+}{ }_{2 i}^{\text {Carava }}+{ }_{3 i}^{\text {Age }}+{ }_{4 i} \text { Male }+{ }_{5 i} \text { Income } \\
& +{ }_{6 i} \text { OWE }+{ }_{7 i} \text { Child }+{ }_{8 i} \text { Subsidy }+{ }_{9 i}^{\text {Residence }}
\end{aligned}
$$

where

$A S C$ stands for the alternative-specific constant;

Time refers to one-way commuting time (in minute) reported by the respondent;

Carava stands for car is available for the respondent to use in work trips;

Male is a dummy variable, with $1=$ male, and $0=$ otherwise;

Income is a categorical variable representing the respondent's income level;

$O W E$ refers to the fact that there are more than one wage earners in the household;

Child represents that the respondent has young child (younger than 18);

Subsidy refers to the respondent receives transport subsidy from employer; and

Residence represents the hypothetical/actual housing location choice after job relocation. 
Following the notation used by Hensher et al. (2005, p. 86), the probability of an individual choosing alternative $i$ out of a choice set of $J$ alternatives is written in Eq. (2):

$$
\operatorname{Prob}_{i}=\frac{\exp V_{i}}{J \exp V_{j}} ; \mathrm{j}=1, \ldots, i, \ldots, J_{i} j
$$

The SP mode choice set contains five alternative transport modes: car, bus, subway, walk, and other. The RP choice set consists of three alternatives, namely, car, public transport, and non-motorized mode. In the RP model, the non-motorized category encompassed 10 observations of choosing cycling and 28 of walking to commute to new town. We use this combined category to ensure each alternative in the RP model estimation will have at least 30 observations - essentially, to follow the rule of thumb for the minimum sample sizes when working with RP data (McFadden, 1984, p. 1442, also cited in Hensher, 2007, p. 161).

\subsubsection{Consistency between the anticipated and actual choice behavioral framework}

Table 5 and 6 reports the best-fit model estimation for the SP and RP data, respectively. The overall model fits provide indication that the models are interpretable (pseudo $\mathrm{R}^{2}=.59$ and $=.32$ for SP model and RP model, respectively). Both the SP and RP model estimations are significant at the $95 \%$ confidence interval.

The main finding is that there are considerable differences between the set of significant predictors estimated from the SP and RP data. The only common place is the effect of car availability - car availability has a positive effect on choosing car over other modes in each of the choice setting. However, as discussed in Section 4.2, the sharp increase in the overall car availability is plausibly an important factor for explaining the greater share of car commuting in the RP survey. As such, while car availability is included as a control variable, our model comparisons might still somehow overestimate the magnitude of car availability on the consistency between the anticipated and actual mode choice after job relocation. Apart from this, the notable differences between the SP and RP model estimations indicate that the underlying behavioral framework is by and large distinctive between the anticipated and actual mode choice after job relocation. The remainder of this section scrutinizes the inconsistency between the SP and RP modal estimates on a variable-by-variable basis, focusing on those variables with significant coefficients.

Travel time: While travel time enters both models with a significant coefficient, it impacts different sets of choice probability, i.e., the relative probability of choosing walkingversus-car in the SP model, and transit-versus-car in the RP model. Based on the SP data, we identify that the increase in one-way commute time would reduce the likelihood of expecting to walk to work after job relocation (Table 5). But, in the actual mode choice setting, the increase in travel time will greater the probability of choosing public transport over car after jobs were relocated to new town (Table 6).

Housing location choice after job relocation: The hypothetical residence after job relocation is positively correlated with the likelihood of expecting to choose subway over car. The stated choice of the rest alternatives (bus, walking and other) is insensitive to the hypothetical residence as if jobs are moved to new town. Nevertheless, after jobs have been eventually relocated, workers' actual choice of where to live is a significant factor to the likelihood of choosing car versus each of the rest transportation means in the RP choice set. Specifically, of those workers who continue living in the central city, they have a lower propensity of choosing non-motorized mode over car, compared with their counterparts who moved housing to new town. Among those workers who moved housing to elsewhere in the city, they have a higher chance of taking public transport to work and lower chance of using 
non-motorized mode instead of driving, relative to their cohorts who moved housing to new town after job relocation.

Socio-demographic characteristics: In the SP model, most of the socio-demographic characteristics have significant effects on the probability of anticipating choosing car over each of rest transport means in the choice set. However, in the RP model, only car availability and age are significantly related to the propensity of choosing car versus other two alternative modes. In relation to age, the SP model indicates that workers in the middle career age (26-35 and 46-55) have a higher propensity to expect to commute by sustainable transport means (e.g., subway and walking), in comparison to their cohorts who just entered the workforce. However, according to the RP model estimation, middle-career workers have lower probability of choosing non-motorized mode over car than their cohorts who just started their career.

While male respondents are found to have a lower propensity to anticipate subway as their future commute mode to new town (relative to their female counterparts), gender does not have significant effect on the actual mode choice. Furthermore, there are four additional significant predictors for workers' anticipated mode choice after job relocation: 1) income, 2) have multiple wage earners, 3) have young child, and 4) receive transport subsidy. But, none of these factors are found to be significant in the actual mode choice setting.

The above SP/RP model comparisons suggest that factors shaping individuals' mode choices change from before to after the actual implementation of GJR policy. When responding to the hypothetical situation of as if jobs were moved to new town, workers' anticipated choices of commuting mode are loosely constrained by the anticipated travel time but largely concerned about the enablers/limits related to their socio-demographic characteristics. After jobs are actually moved to new town, workers' mode choice behaviors are predominantly determined by their actual travel times and housing location choices. In the SP model, the spark of significant coefficients for travel time and housing location might relate to workers' inaccurate prediction of their future commuting times and residence after their jobs are eventually relocated to new town. Another possible explanation would be the issue of hypothetical bias in stated choice experiments - a notion that is closely related to the hypothetical nature of stated choice experiments.

As discussed in previous studies on discrete choice analysis, while SP data has the advantage of forecasting choice responses to new alternatives or policy regulations that are not available in the current market, a major concern of SP data is the bias introduced by the hypothetical nature of stated choice experiments (Hensher, 2010, Hensher et al., 2015, pp. 837-838 and pp. 868-896). As these studies suggest, the deviation of stated choices from their actual counterparts may result from respondents' possible lack knowledge of the full implications of their stated choice. In our study, it is possible that some workers might not have an accurate estimation of changes in travel time after their jobs were actually moved to new town, therefore stating a different commuting mode from the actual mode. Furthermore, these cited studies also indicate that the SP/RP deviation might also relate to the decisionmaking process in which participants are not encountered by real market and personal constraints when responding to stated choice questions. In relation to our empirical setting, it is not impossible that certain number of SP survey respondents may have selected a transport means, e.g., subway, based on an incorrect prediction of the accessibility of this mode in the real market. On the other hand, personal constraints over the anticipated mode choice might be limited, for instance, the financial ability to afford car commuting and the feasibility to walk to the new workplace after job relocation. 
Table 5. MNL model estimation on workers' anticipated mode choice after job relocation, SP sample

\begin{tabular}{|c|c|c|c|c|c|}
\hline Variable & Bus & Subway & Walk & Other & $\begin{array}{c}\text { Car } \\
\text { (base outcome) } \\
\end{array}$ \\
\hline One-way commute time (mins) & $\begin{array}{l}0.00645 \\
(0.0232)\end{array}$ & $\begin{array}{c}0.0274 \\
(0.0258)\end{array}$ & $\begin{array}{c}-0.0929 * * * \\
(0.0336)\end{array}$ & $\begin{array}{l}-0.0199 \\
(0.0181)\end{array}$ & - \\
\hline \multicolumn{6}{|l|}{ Socio-demographic characteristics } \\
\hline $\begin{array}{l}\text { Number of cars available for use } \\
\text { in work trips } \\
\text { Age (18-25) (reference group) }\end{array}$ & $\begin{array}{c}-3.917 * * * \\
(1.101)\end{array}$ & $\begin{array}{l}-0.341 \\
(0.878)\end{array}$ & $\begin{array}{l}-2.752 * * * \\
(0.691)\end{array}$ & $\begin{array}{l}-1.549 * \\
(0.806)\end{array}$ & - \\
\hline Age (26-35) & $\begin{array}{c}1.621 \\
(1.281)\end{array}$ & $\begin{array}{c}2.720 * * \\
(1.163)\end{array}$ & $\begin{array}{l}4.161 * * * \\
(1.112)\end{array}$ & $\begin{array}{l}1.737 * \\
(1.026)\end{array}$ & - \\
\hline Age (36-45) & $\begin{array}{l}-0.162 \\
(1.123)\end{array}$ & $\begin{array}{l}1.545 \\
(1.424)\end{array}$ & $\begin{array}{c}1.290 \\
(1.018)\end{array}$ & $\begin{array}{l}0.0108 \\
(1.039)\end{array}$ & - \\
\hline Age (46-55) & $\begin{array}{l}2.666^{* * *} \\
(1.200)\end{array}$ & $\begin{array}{l}3.779 * * * \\
(1.089)\end{array}$ & $\begin{array}{l}3.299 * * * \\
(1.177)\end{array}$ & $\begin{array}{c}-13.06 * * * \\
(0.972)\end{array}$ & - \\
\hline \multicolumn{6}{|l|}{ Age $(>55)$ (reference group) } \\
\hline Male & $\begin{array}{l}-1.266 \\
(1.176)\end{array}$ & $\begin{array}{l}-2.209 * \\
(1.319)\end{array}$ & $\begin{array}{l}-0.938 \\
(0.880)\end{array}$ & $\begin{array}{l}-0.990 \\
(0.923)\end{array}$ & - \\
\hline $\begin{array}{l}\text { Household yearly income } \\
(0-15,000 \mathrm{RMB})\end{array}$ & $\begin{array}{l}2.636 \\
(2.099)\end{array}$ & $\begin{array}{l}-0.752 \\
(2.291)\end{array}$ & $\begin{array}{c}0.670 \\
(1.850)\end{array}$ & $\begin{array}{l}2.895 * * \\
(1.437)\end{array}$ & - \\
\hline $\begin{array}{l}\text { Household yearly income } \\
(15,001-30,000 \mathrm{RMB})\end{array}$ & $\begin{array}{l}3.224 * * * \\
(1.122)\end{array}$ & $\begin{array}{l}1.950 \\
(1.247)\end{array}$ & $\begin{array}{c}1.194 \\
(0.822)\end{array}$ & $\begin{array}{c}1.079 \\
(1.020)\end{array}$ & - \\
\hline $\begin{array}{l}\text { Household yearly income } \\
\text { (30,001-50,000 RMB) } \\
\text { Household yearly income } \\
\text { (50,001-90,000 RMB) (reference } \\
\text { group) }\end{array}$ & $\begin{array}{l}3.530 * * \\
(1.433)\end{array}$ & $\begin{array}{l}5.121 * * * \\
(1.480)\end{array}$ & $\begin{array}{c}1.323 \\
(0.944)\end{array}$ & $\begin{array}{l}2.383 * * \\
(0.955)\end{array}$ & - \\
\hline $\begin{array}{l}\text { Number of wage earners in the } \\
\text { household }\end{array}$ & $\begin{array}{c}-1.795 * * \\
(0.787)\end{array}$ & $\begin{array}{c}-1.433 * * \\
(0.690)\end{array}$ & $\begin{array}{l}-1.635^{* * * *} \\
(0.574)\end{array}$ & $\begin{array}{c}-1.280 * * \\
(0.545)\end{array}$ & - \\
\hline $\begin{array}{l}\text { Number of young child (under } \\
\text { age 18) }\end{array}$ & $\begin{array}{l}-1.798 * * * \\
(0.681)\end{array}$ & $\begin{array}{l}-0.254 \\
(0.471)\end{array}$ & $\begin{array}{l}-0.635^{*} \\
(0.356)\end{array}$ & $\begin{array}{c}-1.106 * * * \\
(0.402)\end{array}$ & - \\
\hline $\begin{array}{l}\text { Receive toll subsidy from } \\
\text { employer }\end{array}$ & $\begin{array}{l}-14.67 * * * \\
(1.664)\end{array}$ & $\begin{array}{c}0.872 \\
(2.058)\end{array}$ & $\begin{array}{l}0.173 \\
(1.047)\end{array}$ & $\begin{array}{c}-13.83 * * * \\
(1.361)\end{array}$ & - \\
\hline $\begin{array}{l}\text { Receive transit fare subsidy from } \\
\text { employer }\end{array}$ & $\begin{array}{l}-0.741 \\
(1.938)\end{array}$ & $\begin{array}{l}0.0209 \\
(2.213)\end{array}$ & $\begin{array}{c}0.811 \\
(1.558)\end{array}$ & $\begin{array}{l}1.691 \\
(1.486)\end{array}$ & - \\
\hline $\begin{array}{l}\text { Receive parking subsidy from } \\
\text { employer } \\
\text { Receive other subsidy from } \\
\text { employer (reference group) }\end{array}$ & $\begin{array}{l}-0.509 \\
(1.338)\end{array}$ & $\begin{array}{l}-0.0612 \\
(1.311)\end{array}$ & $\begin{array}{c}1.167 \\
(1.202)\end{array}$ & $\begin{array}{l}-0.609 \\
(1.413)\end{array}$ & - \\
\hline \multicolumn{6}{|c|}{ Hypothetical housing location after job relocation } \\
\hline If live in the central city & $\begin{array}{c}1.181 \\
(1.469)\end{array}$ & $\begin{array}{c}6.800 * * * \\
(1.553)\end{array}$ & $\begin{array}{c}1.363 \\
(1.386)\end{array}$ & $\begin{array}{l}-0.367 \\
(1.610)\end{array}$ & - \\
\hline Constant & $\begin{array}{l}3.087 * * \\
(1.546)\end{array}$ & $\begin{array}{l}-4.307 * * * \\
(1.555)\end{array}$ & $\begin{array}{l}4.545^{* * *} * \\
(1.354)\end{array}$ & $\begin{array}{l}3.169^{*} \\
(1.727)\end{array}$ & $\begin{array}{l}0.0000 \\
(.)\end{array}$ \\
\hline Observations & 172 & 172 & 172 & 172 & 172 \\
\hline $\begin{array}{l}\text { Robust standard errors in pare } \\
* * * \mathrm{p}<0.01, * * \mathrm{p}<0.05, * \mathrm{p}<0 \\
\text { Wald chi2 } 2(64)=6565.60 \\
\text { Prob }>\text { chi } 2=0.0000 \\
\text { Pseudo R2 }=0.5851 \\
\text { Log likelihood }=-105.9051\end{array}$ & & & & & \\
\hline
\end{tabular}


Table 6. MNL model estimation on workers' actual mode choice after job relocation, RP sample

\begin{tabular}{|c|c|c|c|}
\hline Variable & Public transport & Non-motorized mode & $\begin{array}{c}\text { Car } \\
\text { (base outcome) }\end{array}$ \\
\hline One-way commute time (mins) & $\begin{array}{c}0.020 * * \\
(0.033)\end{array}$ & $\begin{array}{l}-0.005 \\
(0.759)\end{array}$ & - \\
\hline \multicolumn{4}{|l|}{ Socio-demographic characteristics } \\
\hline Car is available for use in work trips & $\begin{array}{c}-1.505^{* * *} \\
(0.002)\end{array}$ & $\begin{array}{c}-2.854 * * * \\
(0.000)\end{array}$ & - \\
\hline \multicolumn{4}{|l|}{ Age (18-25) (reference group) } \\
\hline Age (26-35) & $\begin{array}{l}-0.352 \\
(0.687)\end{array}$ & $\begin{array}{l}-2.576^{*} \\
(0.067)\end{array}$ & - \\
\hline Age $(36-45)$ & $\begin{array}{l}-0.102 \\
(0.921)\end{array}$ & $\begin{array}{l}-3.721 * * \\
(0.024)\end{array}$ & - \\
\hline Age (46-55) & $\begin{array}{c}0.733 \\
(0.538)\end{array}$ & $\begin{array}{l}-2.563 \\
(0.102)\end{array}$ & - \\
\hline Age $(>55)$ & $\begin{array}{c}2.170 \\
(0.289)\end{array}$ & $\begin{array}{l}-2.667 \\
(0.225)\end{array}$ & - \\
\hline Male & $\begin{array}{l}-0.614 \\
(0.138)\end{array}$ & $\begin{array}{c}0.809 \\
(0.202)\end{array}$ & - \\
\hline \multicolumn{4}{|l|}{$\begin{array}{l}\text { Monthly income }(0-2,999 \mathrm{CNY}) \\
\text { (reference group) }\end{array}$} \\
\hline Monthly income $(3,000$ - 3,999 CNY) & $\begin{array}{l}-0.239 \\
(0.605)\end{array}$ & $\begin{array}{c}0.586 \\
(0.398)\end{array}$ & - \\
\hline Monthly income (4,000 - 4,999 CNY) & $\begin{array}{l}-0.860 \\
(0.338)\end{array}$ & $\begin{array}{c}0.828 \\
(0.353)\end{array}$ & - \\
\hline Monthly income $(5,000$ - 5,999 CNY) & $\begin{array}{r}-12.423 \\
(0.990)\end{array}$ & $\begin{array}{l}-0.442 \\
(0.770)\end{array}$ & - \\
\hline $\begin{array}{l}\text { Have other wage earner in the } \\
\text { household }\end{array}$ & $\begin{array}{l}-0.853 \\
(0.157)\end{array}$ & $\begin{array}{l}-0.903 \\
(0.257)\end{array}$ & - \\
\hline Have young child (under age 18) & $\begin{array}{l}-0.262 \\
(0.589)\end{array}$ & $\begin{array}{c}0.464 \\
(0.478)\end{array}$ & - \\
\hline $\begin{array}{l}\text { Receive transport subsidy from } \\
\text { employer }\end{array}$ & $\begin{array}{c}0.875 \\
(0.239)\end{array}$ & $\begin{array}{l}-1.997 \\
(0.147)\end{array}$ & - \\
\hline \multicolumn{4}{|l|}{$\begin{array}{l}\text { Moved housing to new town (reference } \\
\text { group) }\end{array}$} \\
\hline Moved housing to elsewhere & $\begin{array}{l}1.696^{* *} \\
(0.035)\end{array}$ & $\begin{array}{c}-3.335^{* * *} \\
(0.008)\end{array}$ & - \\
\hline Did not move housing & $\begin{array}{c}1.149 \\
(0.126)\end{array}$ & $\begin{array}{c}-3.773 * * * \\
(0.001)\end{array}$ & - \\
\hline Constant & $\begin{array}{c}0.284 \\
(0.813)\end{array}$ & $\begin{array}{c}5.145^{* * *} \\
(0.003)\end{array}$ & $\begin{array}{c}0.000 \\
(.)\end{array}$ \\
\hline Observations & 192 & 192 & 192 \\
\hline \multicolumn{4}{|l|}{$\begin{array}{l}\text { Robust standard errors in parentheses } \\
* * * \mathrm{p}<0.01, * * \mathrm{p}<0.05, * \mathrm{p}<0.1\end{array}$} \\
\hline \multicolumn{4}{|l|}{$\operatorname{LR} \operatorname{chi} 2(30)=129.81$} \\
\hline \multicolumn{4}{|l|}{ Prob $>$ chi $2=0.0000$} \\
\hline \multicolumn{4}{|l|}{ Pseudo R2 = 0.3226} \\
\hline Log likelihood $=-136.3068$ & & & \\
\hline
\end{tabular}




\section{Conclusion}

This study is the first of a series of papers, forthcoming by the authors, on the modal effect of job decentralization in Chinese cities. It makes unique contributions to the existing literature by generating the first piece of evidence on Chinese workers' anticipated and actual mode-choice responses to a government-led job decentralization policy using both stated and revealed preference data. A review of the literature suggests that job decentralization tends to increase car commuting, in spite of inconsistency in the effect on other forms of transport. Nevertheless, not much is known about the applicability of the knowledge in less-researched context, such as the practice of decentralizing government offices and the geographical context of smaller-medium cities in developing countries. Within the context of Chinese cities, the effect of government-led job decentralization - GJR policy - on workers' commuting mode choices is little examined in the existing literature. This study extends the current literature on the modal effect of job decentralization policy, focusing on workers' anticipated versus actual mode-choice responses to GJR policy in Kunming, China. The use of both SP and RP data provides a richer empirical setting to not only understand overall changes in the anticipated/actual modal split after job relocation to a new town in Kunming's urban outskirt, but also to explore factors influencing the consistency between the anticipated and actual mode-choice responses after job relocation.

The modal split results suggest that within each choice setting (i.e., the anticipated and actual mode choice, respectively), the modal effect of GJR policy tends to vary by different types of housing location choice after job relocation. However, after controlling for housing locations post job resettlement, there are considerable differences between the anticipated and actual mode shifting behaviors in response to job relocation, suggesting a noticeable deviation of the anticipated mode-choice responses from their actual counterparts. Particularly, when responding to the hypothetical setting 'if I live in the central city after my job is moved to Chenggong New Town,' respondents expect to have a significant switching to subway from all other transport means. Nevertheless, this anticipated sustainable transportation outcome does not present in real world after jobs have been eventually moved to new town. Among those workers who actually continue living in the central city and commute to new town, their revealed mode choices in work trips demonstrate a substantial shift from sustainable transport means (i.e., public transit, cycling and walking) to car. The considerable increase in car commuting also occurs across the whole RP sample. The relocation of jobs to new town is accompanied by a statistically significant increase in car commuting and a decrease in public transport and cycling. The change in walking mode share is not statistically significant.

In order to identify the possible causes underlying the anticipated-versus-actual deviation observed at the aggregated level, we specify two sets of MNL model - one on the SP data and another on the RP data - with a focus on exploring factors influencing workers' anticipated/actual mode choices after job relocation. The comparison between the SP and RP model estimations suggest that workers' anticipated and actual mode choices are influenced by two different sets of factors, with only one significant predictor - car availability - shares in common. Through comparing significant predictors for anticipated/actual mode choices on a variable-by-variable basis, this study demonstrates that the driving forces of individuals' mode choices change from before to after the actual implementation of GJR policy. Such shift in the behavioral framework is featured by the move from being loosely constrained by the anticipated travel time and largely concerned about the enablers/limits related to sociodemographic characteristics at the time when responding to the planned job relocation program, to focusing on actual travel time and housing locations after jobs were actually moved.

We consider that the directional and magnitude differences between the SP and RP model estimations might result from two main factors: 1) perceptual errors about future travel time and residence after their jobs are eventually moved to new town; and 2) the hypothetical nature of the stated choice experiments, such as workers might anticipate their mode choice without subject to personal constraints. While it is out of the scope of this study to quantify the exact size of hypothetical bias in workers' anticipated mode choice, we make an 
important attempt to capture the deviation between the anticipated and actual choice behavioral framework through comparing factors shaping participants' stated versus revealed mode choices after job relocation. We add this humble piece of evidence to the scare body of literature on the issue of hypothetical bias in transportation-related stated choice experiments (cf. Hensher, 2010, for an excellent discussion on the lack of empirical evidence on this regard).

Key findings from this study also offer important implications for future planning practice of employment decentralization in Chinese cities and beyond. While this study focuses on a particular form of job decentralization policy in China - the GJR policy implemented in China's new town development, the significant shift to car commuting after the implementation of GJR policy in our case study is consistent with the prior experience documented in North American and European cities. Through adding a new piece of evidence from this present study, we argue that planners and policy-makers should be skeptical about the often-touted transportation benefits of job decentralization. Meanwhile, in the case of staged implementation of job decentralization policy, SP surveys can assist transportation planners to predict workers' mode-choice responses, but the robustness of SP results should be carefully assessed before translating into the evidence base for policymaking.

\section{Acknowledgements}

We would like to acknowledge the University of Melbourne for the fieldwork funding to support RP data collection and for the generous scholarship granted to the first author. The authors would also like to acknowledge Professor $\mathrm{He}$ Min and the numerous students at Kunming University of Science and Technology for assisting with survey development and SP data collection. In addition, the authors would like to acknowledge the National Science Foundation Ease Asia and Pacific Summer Institutes for U.S. Graduate Students (EAPSI) and the National Science Foundation Chemical, Bioengineering, Environmental, and Transport Systems (CBET) grant 1055282 for support during SP data collection. Also, we would like to acknowledge IACP for arranging this special issue. Last but not the least, we would like to thank the three anonymous reviewers for their valuable comments to improve our work.

\section{References:}

AGUILÉRA, A., WENGLENSKI, S. \& PROULHAC, L. 2009. Employment suburbanisation, reverse commuting and travel behaviour by residents of the central city in the Paris metropolitan area. Transportation Research Part A: Policy and Practice, 43, 685-691.

ALPKOKIN, P., CHEUNG, C., BLACK, J. \& HAYASHI, Y. 2008. Dynamics of clustered employment growth and its impacts on commuting patterns in rapidly developing cities. Transportation Research Part A: Policy and Practice, 42, 427-444.

BANISTER, D., WATSON, S. \& WOOD, C. 1997. Sustainable cities: Transport, energy, and urban form. Environment \& Planning B: Planning \& Design, 24, 125-143.

BURKE, M., LI, T. \& DODSON, J. 2011. What Happens When Government Workers Move to the Suburbs? Impact on Transport of Planned Decentralization of Employment in Brisbane, Australia. Transportation Research Record, 2255, 110.

CERVERO, R. \& LANDIS, J. 1992. Suburbanization of jobs and the journey to work: a submarket analysis of commuting in the San Francisco Bay Area. 
CERVERO, R. \& WU, K.-L. 1998. Sub-centring and Commuting: Evidence from the San Francisco Bay Area, 1980-90. Urban Studies (Routledge), 35, 1059-1076.

CERVERO, R. \& WU, K. L. 1997. Polycentrism, commuting, and residential location in the San Francisco Bay Area. Environment \& Planning A, 865.

CHERRY, C. \& CERVERO, R. 2007. Use characteristics and mode choice behavior of electric bike users in China. Transport Policy, 14, 247-257.

CHERRY, C. R., YANG, H., JONES, L. R. \& HE, M. 2016. Dynamics of electric bike ownership and use in Kunming, China. Transport Policy, 45, 127-135.

CHINA.ORG.CN. 2014. Chenggong Overview [Online]. Available: http://www.china.com.cn/news/zhuanti/2014dc/201408/21/content 33304298 3.htm [Accessed 25 September 2015].

DANIELS, P. W. 1972. Transport Changes Generated by Decentralized Offices. Regional Studies, 6, 273-289.

DANIELS, P. W. 1981. Transport changes generated by decentralized offices: A second survey. Regional Studies, 15, 507.

DE WITTE, A., HOLLEVOET, J., DOBRUSZKES, F., HUBERT, M. \& MACHARIS, C. 2013. Linking modal choice to motility: A comprehensive review. Transportation Research Part A: Policy and Practice, 49, 329-341.

HENSHER, D. A. 2007. Bus Transport: Economics, Policy and Planning, Burlington, Elsevier Science.

HENSHER, D. A. 2010. Hypothetical bias, choice experiments and willingness to pay. Transportation Research Part B: Methodological, 44, 735-752.

HENSHER, D. A., ROSE, J. M. \& GREENE, W. H. 2005. Applied Choice Analysis : A Primer, Cambridge : Cambridge University Press, 2005.

HENSHER, D. A., ROSE, J. M. \& GREENE, W. H. 2015. Applied Choice Analysis, Cambridge, Cambridge University Press.

KMUPDI 2012. Kunming Master Plan (2008-2020) UPDATE. Kunming Urban Planning \& Design Institute.

LIN, D., ALLAN, A. \& CUI, J. 2015. The impact of polycentric urban development on commuting behaviour in urban China: Evidence from four sub-centres of Beijing. Habitat International, 50, 195-205.

LIU, Y., YIN, G. \& MA, L. J. C. 2012. Local state and administrative urbanization in post-reform China: A case study of Hebi City, Henan Province. Cities, 29, 107-117.

MCFADDEN, D. L. 1984. Chapter 24 Econometric analysis of qualitative response models. Handbook of Econometrics, 2, 1395-1457.

MØLLER, J. S. \& NÆSS, P. 2000. Workplace location and modal choice: The case of Aalborg (Arbejdspladslokalisering ogtransportmiddelvalg ved boligarbejdsrejser - eksemplet Aalborg) Byplan, 6, 238-247.

NÆSS, P. 2012. Urban form and travel behavior: Experience from a Nordic context. Journal of Transport and Land Use, 5, 21-45.

NÆSS, P. \& SANDBERG, S. L. 1996. Workplace Location, Modal Split and Energy Use for Commuting Trips. Urban Studies (Routledge), 33, 557-580.

SIM, L. L., MALONE-LEE, L. C. \& CHIN, K. H. L. 2001. Integrating land use and transport planning to reduce work-related travel:. a case study of Tampines Regional Centre in Singapore. Habitat International, 25, 399-414.

VALE, D. S. 2013. Does commuting time tolerance impede sustainable urban mobility? Analysing the impacts on commuting behaviour as a result of workplace relocation to a mixed-use centre in Lisbon. Journal of Transport Geography, 32, 38-48. 
VAN ACKER, V., VAN WEE, B. \& WITLOX, F. 2010. When Transport Geography Meets Social Psychology: Toward a Conceptual Model of Travel Behaviour. Transport Reviews, 30, 219-240.

WABE, J. S. 1967. Dispersal of Employment and the Journey to Work: A Case Study. Journal of Transport Economics and Policy, 1, 345-361.

WANG, E., SONG, J. \& XU, T. 2011. From "spatial bond" to "spatial mismatch": An assessment of changing jobs-housing relationship in Beijing. Habitat International, 35, 398-409.

YANG, J. 2010. Spatial and Social Characteristics of Urban Transportation in Beijing. Transportation Research Record, 2193, 59-67.

YANG, J., SHEN, Q., SHEN, J. \& HE, C. 2012. Transport Impacts of Clustered Development in Beijing: Compact Development versus Overconcentration. Urban Studies, 49, 1315-1331.

YANG, X. \& DAY, J. 2015. Operationalizing the Capabilities Approach for Urban Policy Evaluation: The Travel Welfare Impacts of Government Job Resettlement. Geographical Research Forum, 35, 113-137.

YANG, X. \& DAY, J. 2016. Operationalizing the Capabilities Approach for Modeling Household Welfare Shifts in Urban Systems: A Special Focus on the Transportation Outcomes of Urban Resettlement. In: WALLOTH, C., GEBETSROITHER-GERINGER, E., ATUN, F. \& WERNER, L. C. (eds.) Understanding Complex Urban Systems: Integrating Multidisciplinary Data in Urban Models. Switzeland: Springer International Publishing.

YANG, X., DAY, J. \& HAN, S. S. 2015. Urban Peripheries as Growth and Conflict Spaces: The Development of New Towns in China. In: WONG, T.-C., HAN, S. S. \& ZHANG, H. (eds.) Population Mobility, Urban Planning and Management in China. Switzerland: Springer International Publishing AG.

YANG, X., DAY, J., LANGFORD, C., CHERRY, C., JONES, L. \& HAN, S. S. in press. Stated versus revealed residential location choices in response to job resettlement to new towns: a case study of Kunming, China. World Conference on Transport Research (WCTR). Shanghai: Transportation Research Procedia.

YIN, R. K. 2014. Case study research: design and methods, Thousand Oaks, SAGE Publications, Inc.

YNPG. 2015. Envisaging the vision for Chenggong [Online]. Chenggong Economy, Trade and Investment Promotion Bureau. Available: http://xxgk.yn.gov.cn/Z_M_012/Info_Detail.aspx?DocumentKeyID=c773818

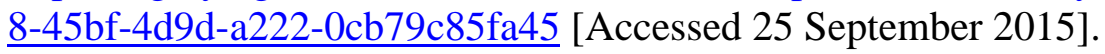

